\title{
AS ARTICULAÇÕES ENTRE AS ATIVIDADES DO CURSO E O PAPEL DO PROFESSOR QUE ENSINA MATEMÁTICA NOS CURSOS DE ENGENHARIA
}

DOI: 10.37702/2175-957X.COBENGE.2021.3625

Stefane Layana Gaffuri - stefanegaffuri@gmail.com

Universidade Tecnológica Federal do Paraná

Rua Manoel Isidoro da Silveira 199

88062-130 - Florianópolis - SC

Walter Antonio Bazzo - walter.bazzo@ufsc.br

UFSC

UFSC Campus Uni

88049-900 - Florianópolis - SC

Paula Andrea Grawieski Civiero - paula.civiero@ifc.edu.br

Instituto Federal Catarinense

Rua México 255

89165-643 - Rio do Sul - SC

Resumo: A complexidade e a diversificação de solicitações que hoje se colocam na sociedade têm despertado questionamentos quanto à adequação dos currículos dos cursos superiores, bem como a formação do professor perante o desenvolvimento tecnológico e humano dos estudantes. Ao analisar a formação dos engenheiros, isso é ainda mais desafiador, visto que esses profissionais têm sua carreira pautada em um mercado de trabalho que está em constante transformação, o que Ihes cobra atualização contínua e altas exigências de formação. Diante disso, nesse artigo são analisados o sexto e o décimo quarto artigo das novas Diretrizes Curriculares Nacionais para os cursos de engenharia (resolução CNE/CES no 2/2019), com o objetivo de fazer interlocuções entre as atividades do curso e a prática docente, ao refletir sobre como o ensino de matemática pode contribuir para analisar as soluções dos desafios contemporâneos desse profissional. Para isso, defende-se a importância da inclusão de atividades com enfoque em Ciência, Tecnologia e Sociedade (CTS), que busquem compreender e encontrar subsídios para proporcionar um estudo crítico e interdisciplinar da ciência e da tecnologia no contexto atual. Para conduzir o 


\section{COBENGE e I Simpósio Internacional

estudante a uma visão mais ampla dos modelos matemáticos, conclui-se ser necessário integrar habilidades técnicas às competências interdisciplinares da matemática, ao explorar também variáveis sociais e humanas, relacionando-as com as dimensões tecnológicas, científicas, econômicas, sociais, ambientais e éticas, e assim aproximar a formação do egresso do contexto social.

Palavras-chave: Educação em Engenharia; Diretrizes Curriculares Nacionais; Formação Docente; Educação Matemática; CTS. 


\section{AS ARTICULAÇÕES ENTRE AS ATIVIDADES DO CURSO E O PAPEL DO PROFESSOR QUE ENSINA MATEMÁTICA NOS CURSOS DE ENGENHARIA}

\section{INTRODUÇÃO}

A complexidade e a diversificação de solicitações que hoje se colocam na sociedade têm avivado os questionamentos quanto a importância que a universidade tem no desenvolvimento tecnológico e humano, bem como sua adequação ao sistema e aos desafios contemporâneos. Ao pensar na formação dos engenheiros, isso é ainda mais desafiador, visto que esses profissionais têm sua carreira pautada em um mercado de trabalho que está em constante transformação, o que lhes cobra atualização contínua, altas exigências de formação técnica e um intercâmbio de experiências.

Nesse contexto, cabe ao curso de engenharia e a aos professores um papel especial, posto que "[...] continuam a ser vistos como agentes efetivos de mudança, deles dependendo, em grande parte, tanto as transformações que urge imprimir na escola e no ensino, quanto ao sucesso educativo dos estudantes e a sua realização como pessoa" (MORGADO, 2011, p. 795). Entretanto, o profissional docente atravessa uma fase difícil. Com a evolução da tecnologia e a desvalorização profissional, estão sendo cada vez mais substituídos pela máquina. Para Monteiro (2009, p. 4), "a profissão docente está em declínio, tanto por se ter tornado uma profissão mais complexa e exigente, como por ser exercida em condições que não ajudam".

Excesso de trabalho, jornada tripla e baixo salário; pressão do sistema educacional e do mercado de trabalho; ensino remoto, ensino hibrido e a revolução tecnológica; formação inicial deficiente, formação continuada inexistente e um bombardeio de informações que gera um desgaste físico e mental e, em particular, a falta de reconhecimento de sua atividade. Essas seriam algumas causas do estresse, da ansiedade e da depressão que vêm acometendo os professores e, em muitos casos, causando o abandono da profissão. Por isso, cabe olhar com cuidado para as relações entre as atividades do curso de engenharia, a competência profissional exigida, a identidade profissional e profissionalidade docente dentro de um processo que exige valorização e formação contínua.

As novas Diretrizes Curriculares Nacionais (DCNs) objetivam a formação do engenheiro para inovar, empreender e exercer atividades formativas nas áreas de tecnologia e engenharia. Com o uso da flexibilização de projetos pedagógicos, e com a mudança da concepção de currículo por conteúdos para currículo por competências e a adoção de metodologias ativas de aprendizagem, as novas diretrizes pretendem colocar o estudante como agente ativo no processo de aprendizagem e o professor como orientador em uma tentativa de atualizar os currículos de engenharia.

Para que isso aconteça, as articulações entre as atividades do curso e papel do professor são essenciais no processo formativo dos futuros engenheiros. Diante disso, nesse artigo são analisados o sexto e o décimo quarto artigo das novas DCNs (resolução CNE/CES no 2/2019), com o objetivo de fazer interlocuções entre essas atividades e a prática docente ao pensar sobre os desafios contemporâneos dessa profissão, as questões sociocientíficas e uma formação humana do engenheiro ao repensar o ensino de matemática para além de uma formação apenas técnica. 


\section{ATIVIDADES DO CURSO}

Segundo a resolução (CNE/CES no 2/2019) que contempla as DCNs para os cursos de Engenharia, as atividades do curso são previstas no artigo sexto, e contemplam uma aprendizagem focada no desenvolvimento de competências.

Art. 6ㅇ $\mathrm{O}$ curso de graduação em Engenharia deve possuir Projeto Pedagógico do Curso (PPC) que contemple o conjunto das atividades de aprendizagem e assegure 0 desenvolvimento das competências, estabelecidas no perfil do egresso. [...]

$\S 1^{\circ}$ É obrigatória a existência das atividades de laboratório, tanto as necessárias para o desenvolvimento das competências gerais quanto das específicas, com o enfoque e a intensidade compatíveis com a habilitação ou com a ênfase do curso.

$\S 2^{\circ}$ Deve-se estimular as atividades que articulem simultaneamente a teoria, a prática e 0 contexto de aplicação, necessárias para 0 desenvolvimento das competências, estabelecidas no perfil do egresso, incluindo as ações de extensão e a integração empresa-escola.

§ 3ํ. Devem ser incentivados os trabalhos dos discentes, tanto individuais quanto em grupo, sob a efetiva orientação docente.

§ 4 Devem ser implementadas, desde o início do curso, as atividades que promovam a integração e a interdisciplinaridade, de modo coerente com o eixo de desenvolvimento curricular, para integrar as dimensões técnicas, científicas, econômicas, sociais, ambientais e éticas.

$\S 5^{\circ}$ Os planos de atividades dos diversos componentes curriculares do curso, especialmente em seus objetivos, devem contribuir para a adequada formação do graduando em face do perfil estabelecido do egresso, relacionando-os às competências definidas.

§ 60 Deve ser estimulado o uso de metodologias para aprendizagem ativa, como forma de promover uma educação mais centrada no aluno. $\S 7^{\circ}$ Devem ser implementadas as atividades acadêmicas de síntese dos conteúdos, de integração dos conhecimentos e de articulação de competências.

$\S 8^{\circ}$ Devem ser estimuladas as atividades acadêmicas, tais como trabalhos de iniciação científica, competições acadêmicas, projetos interdisciplinares e transdisciplinares, projetos de extensão, atividades de voluntariado, visitas técnicas, trabalhos em equipe, desenvolvimento de protótipos, monitorias, participação em empresas juniores, incubadoras e outras atividades empreendedoras.

$\S$ 9 É recomendável que as atividades sejam organizadas de modo que aproxime os estudantes do ambiente profissional, criando formas de interação entre a instituição e o campo de atuação dos egressos.

$\S 10$ Recomenda-se a promoção frequente de fóruns com a participação de profissionais, empresas e outras organizações públicas e privadas, a fim de que contribuam nos debates sobre as demandas sociais, humanas e tecnológicas para acompanhar a evolução constante da Engenharia, para melhor definição e atualização do perfil do egresso.

$\S 11$ Devem ser definidas as ações de acompanhamento dos egressos, visando à retroalimentação do curso. 
$\S 12$ Devem ser definidas as ações de ensino, pesquisa e extensão, e como contribuem para a formação do perfil do egresso. (BRASIL, 2019, grifo próprio).

Nesse artigo, as diretrizes fazem referência às atividades que devem permear o curso, ampliando as que estavam previstas na resolução anterior (CNE/CES no 11/2002). Destaca-se dentre essas, desde o início do curso, a implementação de atividades coletivas de integração e de interdisciplinaridade, "de modo coerente com o eixo de desenvolvimento curricular, para integrar as dimensões técnicas, científicas, econômicas, sociais, ambientais e éticas" (BRASIL, 2019). Também se incentiva uma aprendizagem ativa, onde o estudante possa ser agente do processo, e o professor um orientador e condutor do bom andamento dessas atividades.

Dentro desse contexto cabe considerar como os cursos de engenharia vão enfatizar a importância de integrar as técnicas às competências ao relacionar as dimensões tecnológicas, científicas, econômicas, sociais, ambientais e éticas, ao conduzir o estudante de engenharia a uma visão mais ampla e assim aproximar a formação do egresso com os desafios contemporâneos. Ao analisar os parágrafos 2, 3 e 4 constata-se a importância do debate de questões interdisciplinares em grupo para desenvolver habilidades que vão além das apenas técnicas.

Para isso, cabe considerar as questões sociocientíficas, principalmente as variáveis sociais e humanas, com o objetivo de conduzir o estudante de engenharia a uma visão crítica na identificação e resolução de problemas. Segundo Reis (2006, p. 66), essas questões são

[...] relativas às interações entre ciência, tecnologia e sociedade (nomeadamente, as polêmicas despoletadas pelos eventuais impactos sociais de inovações científicas e tecnológicas), que dividem tanto a comunidade científica como a sociedade em geral, e para as quais diferentes grupos de cidadãos propõem explicações e tentativas de resolução incompatíveis, baseadas em valores alternativos. Essas questões sociocientíficas possuem uma natureza contenciosa, podem ser analisadas segundo diferentes perspectivas, não conduzem a conclusões simples e envolvem, frequentemente, uma dimensão moral e ética.

Para Gaffuri et al (2020) essas problematizações indicam a necessidade de currículos articulados em torno do enfoque Ciência Tecnologia e Sociedade (CTS), pois para os autores "todas as disciplinas se articulam em volta do entendimento de que o fazer da engenharia tem fortes e importantes implicações no contexto social, mais que isso: as questões sociais, em geral, precisam ser os elementos definidores das soluções tecnológicas" (GAFFURI et al, 2020, p.12).

Ressalta-se que, para desenvolver competências, como preconizam as DCNs, através das atividades do curso, os futuros engenheiros precisam ter a capacidade de ponderar sobre múltiplos aspectos, entre eles os sociais, políticos e econômicos, ambientais e culturais, ou seja, é necessário conceber a educação em engenharia alicerçada a debates consistentes e conscientes sobre essas questões, como recomenda o décimo parágrafo do artigo 6ำ (BRASIL, 2019).

Para isso, é importante a inclusão de atividades CTS, pois constituem um campo de trabalho que compreende entender "os aspectos sociais do fenômeno científicotecnológico, tanto no que diz respeito às suas condicionantes sociais como no que diz respeito às suas consequências sociais e ambientais" (BAZZO; LINSINGEN, PEREIRA, 2016, p. 151). Em outras palavras, essas atividades buscam compreender e encontrar 
subsídios para proporcionar um estudo crítico e interdisciplinar da ciência e da tecnologia no contexto de desenvolvimento social.

A partir disso, coloca-se em foco o poder interdisciplinar da matemática que é pouco utilizado nos cursos de Engenharia, por simplesmente a usarem como ferramenta ou linguagem, também pelo uso de metodologias tradicionais e aulas totalmente expositivas, sem a exploração de todo seu potencial.

Aliado a isso, destaca-se o sexto parágrafo, que estimula "[...] as atividades que articulem simultaneamente a teoria, a prática e o contexto de aplicação" e ainda, o "[...] uso de metodologias ativas para aprendizagem, como forma de promover uma educação mais centrada no aluno". E também o parágrafo oitavo que diz que, atividades como os "[...] projetos interdisciplinares e transdisciplinares, projetos de extensão" devem ser estimuladas (BRASIL, 2019, p. 5).

No caso do ensino de matemática nos cursos de engenharia, é necessário considerar os modelos matemáticos como suporte para o desenvolvimento tecnológico e sua inserção nas questões sociocientíficas, principalmente, é necessário analisar como a matemática em ação opera na sociedade. Para isso, também é preciso considerar o poder formatador da matemática, isto é, a relação entre conhecimento matemático e poder (SKOVSMOSE, 2007).

A Matemática faz parte da "certeza" que transforma a sociedade industrial numa sociedade de risco. Desta maneira, entendo que a Matemática em Ação faz parte dos processos sociotecnológicos que, ao produzirem efeitos e efeitos colaterais, transformam a sociedade e caracterizam a modernização reflexiva. Em outras palavras, acho que a modernização reflexiva somente pode ser apreendida se nos tornarmos conscientes das formas que a Matemática em Ação pode assumir (Skovsmose, 2009, p. 35).

Skovsmose (2007), ao definir uma concepção crítica da matemática, propõe considerar o conceito da Matemática em Ação, visto que a Matemática está em todo lugar e se "movimenta em muitas direções". Isso é um desafio para a educação matemática, ou seja, como esta educação pode praticar diferentes funções sociais, em diferentes contextos e grupos de pessoas. Skovsmose (2007, p. 106-107) classifica esses grupos em construtores, operadores, consumidores e marginalizados.

As práticas de construção são "todo tipo de construção e elaboração de tecnologias em que a matemática é empregada" (SKOVSMOSE, 2007, p. 106). As práticas de operação são "procedimentos que envolvem matemática, como aqueles exercidos por laboratoristas, contadores, agentes de viagens etc." (SKOVSMOSE, 2007, p. 106). Nas práticas de consumo, a matemática não aparece de modo explícito, mas na "compra ou aquisição de todo tipo de bens, seja frequentando lojas, assistindo TV, viajando etc." (SKOVSMOSE, 2007, p. 107). No caso das práticas dos marginalizados, são "situações pelas quais passam esse enorme contingente de pessoas que estão alijadas da ordem econômica globalizada" (SKOVSMOSE, 2007, p. 107).

Em todas essas práticas, a matemática aparece como um elemento a ser incluído em suas competências. Assim, defende-se que os cursos de engenharia que buscam adequar seus currículos por competências devem considerar proporcionar aos futuros engenheiros o conhecimento da ambivalência das técnicas matemáticas. Isso significa ir além de práticas como modelar, prever, verificar e validar modelos através de métodos adequados, de modo a prepará-los para agirem com ética e serem responsáveis por essa ação. 
Para que isso aconteça, torna-se necessário uma reflexão por parte dos professores. Para estes assumirem tais responsabilidades, inicialmente, é preciso que algumas premissas façam parte de seus questionamentos como educadores. E necessário questionar as competências para quê, para quem e por quê. Segundo Bazzo, Pereira e Bazzo (2014, p. 73, grifo próprio), os docentes precisam refletir e analisar sobre

[...] as implicações da ciência e da tecnologia junto à sociedade contemporânea; a relação que compromete o ensino desenvolvido nas escolas e a atuação do futuro profissional na sociedade; a história, não só da construção dos artefatos, mas principalmente das ideias que permeiam o desenvolvimento científico-tecnológico; as modificações processadas no mercado de trabalho, que por certo, apontarão a necessidade de novas formações profissionais.

Ao pensar sobre os engenheiros em formação, sobretudo em disciplinas básicas, como a matemática, questiona-se como esta, através do aprimoramento e da utilização das técnicas, pode ampliar e enriquecer essa formação ao considerar os diversos aspectos sociais. Há uma urgência em repensar esse trio: matemática, tecnologia e engenharia, em especial na educação tecnológica pois é necessário "capacitar os cidadãos com competência crítica para questionar as decisões tecnocientíficas, bem como participar ativamente delas" (CIVIERO, 2016, p. 243). Para além das dificuldades conceituais e do uso das ferramentas matemáticas para a resolução de problemas de engenharia, é preciso questionar a pouca ênfase dada às variáveis de cunho social que podem - e devem - ser incorporadas às soluções tecnológicas em desenvolvimento.

Essas inquietações constituem questionamentos pertinentes e novos ambientes de aprendizagem surgem nesse cenário. Esses novos ambientes, chamados de ambientes ativos, se caracterizam por um estudante autônomo, tendo o professor como orientador. Ao aprofundar esse quesito, não se pode ignorar o papel do professor e a necessidade de uma formação continuada de qualidade, algo também previsto nas diretrizes atuais.

\section{O PAPEL DO PROFESSOR QUE ENSINA MATEMÁTICA NO CURSO DE ENGENHARIA}

O artigo $14^{\circ}$ da resolução atual estabelece que:

Art. 14. O corpo docente do curso de graduação em Engenharia deve estar alinhado com o previsto no Projeto Pedagógico do Curso, respeitada a legislação em vigor.

$\S 1^{\circ} \mathrm{O}$ curso de graduação em Engenharia deve manter permanente Programa de Formação e Desenvolvimento do seu corpo docente, com vistas à valorização da atividade de ensino, ao maior envolvimento dos professores com o Projeto Pedagógico do Curso e ao seu aprimoramento em relação à proposta formativa, contida no Projeto Pedagógico, por meio do domínio conceitual e pedagógico, que englobe estratégias de ensino ativas, pautadas em práticas interdisciplinares, de modo que assumam maior compromisso com o desenvolvimento das competências desejadas nos egressos. $\S 2^{\circ} A$ instituição deve definir indicadores de avaliação e valorização do trabalho docente nas atividades desenvolvidas no curso. (BRASIL, 2019, p. 6, grifo próprio). 
Nesse cenário, é preciso considerar o atual contexto, sobre como os estudantes estão "entrando" na universidade, sobre os fundamentos de aprendizagem e principalmente sobre a autonomia destes estudantes em relação aos métodos e técnicas que são difundidos. Há também que se repensar a postura por parte dos docentes que atuam nesses cursos. Para isso, as diretrizes atuais propõem "[...] manter permanente Programa de Formação e Desenvolvimento do seu corpo docente, com vistas à valorização da atividade de ensino" (BRASIL, 2019, p. 6).

A partir dessa perspectiva da orientação, da construção de experiências, do desenvolvimento de competências, faz-se necessário o questionamento sobre quais saberes o professor de Engenharia necessita para exercer essa tarefa. É necessária uma constante reflexão do porquê e para quem esse conhecimento está sendo desenvolvido. É importante, sim, que o professor esteja preparado para os novos desafios da sociedade, mas também considerar para onde essa civilização está caminhando.

Para Bazzo, Pereira e Linsingen (2016, p. 194-195), o professor que atua nos cursos de engenharia,

deve ter consciência de seu entorno social, de seus compromissos e responsabilidades perante os coletivos que participa. Para formar tal cidadãoprofissional consciente, assim acreditamos, precisamos de outros profissionais que extrapolem a visão puramente técnica das coisas à nossa volta. Assim, julgamos que, para formar formadores de profissionais técnicos, precisamos instigá-los e perturbá-los com a própria técnica e construir junto com eles reflexões que permitam a ambos os participantes desse processo discernir com certa clareza as estruturas epistemológicas, social e histórica que permeiam essa técnica. Devemos também instigá-los e perturbá-los dentro da lógica que permita internalizações de novos saberes (2016, p. 194-195).

Para isso, cabe entender as relações entre competência profissional, identidade profissional e profissionalidade docente dentro de um processo que exige valorização e formação contínua. A construção de sua identidade profissional é um processo que ocorre ao longo da vida profissional, isto é, é um processo de especialização e socialização, "já que não envolve apenas a aprendizagem de conceitos e capacidades, mas também de apropriação de valores e atitudes, através da qual o candidato ao exercício da profissão aprende uma postura profissional" (MORGADO, 2011, p. 797).

No que diz respeito às competências profissionais, o autor as chama de "saber profissional" que se consolida no ato de ensinar. Assim, compreende-se que esse saber vai além do "mero domínio de um conjunto de conhecimentos científicos e metodológicos da ciência" que ministra, mas de "compreender as relações entre o processo educativo, a escola e a cultura" (MORGADO, 2011, p. 799). Assim, saber e identidade profissional situam-se no conceito do que é ser professor, especificamente no conceito de profissionalidade docente. Entendido como uma união de três aspectos: desenvolvimento de competências e da identidade profissional, formação continuada ao longo da carreira docente e autonomia do professor. Por conseguinte, os professores ocupam um papel singular na formação dos engenheiros - e de todas as outras profissões.

No caso específico do professor de matemática, que atua no curso de engenharia, faz parte de um desafio ainda maior. Nesses cursos, o conhecimento matemático é compreendido como ferramenta indispensável para o desenvolvimento tecnológico, por isto, é muito valorizada. Sendo o professor considerado um "embaixador da matemática", termo utilizado por Skovsmose (2014) ao abordar a racionalidade da matemática, muito presente nas escolas de engenharia.

Portanto, faz-se necessário analisar alguns aspectos da profissão, especificamente desse docente diante dos desafios atuais. Destacam-se: políticas educacionais e 
curriculares, a formação inicial dos professores, a formação continuada e o currículo que se desenvolve nas escolas de engenharia.

$\mathrm{Na}$ concepção epistemológica, segundo Ledoux e Gonçalves (2015), a formação do professor é entendida como um exercício diário em que a prática docente e os conhecimentos apreendidos na formação associam-se aos conhecimentos que se estabelecem das/nas relações com o exercício da profissão - e isto pode trazer um novo sentido e um novo significado à própria formação.

Esses novos sentidos e significados são elementos subjetivos e pessoais que estão situados na construção da identidade de "ser" professor. E, esses elementos fazem parte da construção da identidade do professor e não se distanciam de outros elementos que também são necessários para que essa construção seja singular em cada indivíduo concreto. Esses outros elementos são os saberes (LEDOUX; GONÇALVES, 2015).

Para além do saber pedagógico do conteúdo, outros saberes estão inseridos no ato de ensinar. Tardif (2014) considera o saber docente como "plural", proveniente da formação profissional (o conjunto de saberes transmitidos pelas instituições de formação de professores), de saberes disciplinares (saberes que correspondem ao diverso campo do conhecimento e emergem da tradição cultural), curriculares (programas escolares) e experienciais (do trabalho cotidiano). O saber além de ser plural, é também temporal. Ele é adquirido no contexto de uma história de vida e de uma carreira profissional que remete à história de sua formação e de sua aquisição. Sobre isso, convém destacar que

A relação dos docentes com os saberes não se reduz a uma função de transmissão dos conhecimentos já constituídos. Sua prática integra diferentes saberes, com os quais o corpo docente mantém diferentes relações. Pode-se definir o saber docente como um saber plural, formado, pelo amálgama, mais ou menos coerente, de saberes oriundos da formação profissional e de saberes disciplinares, curriculares e experimentais. (TARDIF, 2014, p. 36).

A partir da perspectiva da construção de saberes oriundos da formação, expõe-se o questionamento feito por Ponte (1998), sobre quais saberes então precisa o professor de Matemática para exercer sua atividade profissional. $O$ autor sinaliza que, para o professor de matemática desenvolver sua profissão, deve levar em consideração os seguintes aspectos:

- conhecer bem e relacionar-se com as matemáticas (Matemática da academia e das práticas sociais) a serem ensinadas e aprendidas pelo estudante;

- conhecer e adaptar o currículo ao contexto do estudante;

- combinar os diversos métodos e técnicas, tendo em vista os objetivos e o conteúdo;

- conhecer os alunos e o modo como aprendem;

- saber investigar sua própria prática;

- conhecer o contexto de trabalho e a complexidade das aulas de Matemática, ou seja, analisar como ocorrem as práticas e o conhecimento em sala de aula;

- conhecer a si mesmo.

Ao pensar sobre esses aspectos, enfatiza-se que a formação do professor, além de todos os aspectos já postos, faz-se de um processo identitário do próprio docente. Dessa maneira, sobre quais identidades? O professor que ensina matemática tem uma identidade diferente dos demais nos cursos de Engenharia? 
Para o professor que ensina Matemática, há um processo para além de suas interações internas, externas e sua prática. Há um movimento entre os elementos constitutivos da relação entre o conhecimento matemático técnico, a matemática como ferramenta e sua aplicabilidade, bem como o poder da matemática em ação.

Além disso, Paiva e Nacarato (2013), em seus estudos, indicam que a identidade dos professores que ensinam matemática pode sofrer interferências dos interesses políticos, das modificações estruturais dos cursos (ou da própria escola/universidade) e do papel desempenhado pelo professor. Esses aspectos são vinculados aos saberes oriundos da formação, de modo que o conhecimento matemático passa a ser ensinado e incorporado às práticas de ensino. É bem sabido que ensinar Matemática requer, afora o domínio de conteúdos disciplinares específicos, a elaboração e a utilização de singularidades didáticopedagógicas.

De acordo com estudos de Morgado (2011), a identidade profissional do professor não pode ser considerada um dado imutável, mas é um processo de construção do sujeito historicamente situado. A profissão de professor, como as demais, emerge num dado momento e contexto histórico como resposta às necessidades que foram postas pelas sociedades. Assim, o segundo aspecto diz respeito à formação continuada dos professores que pode ser uma contribuição para os docentes questionarem suas práticas de ensino; identificarem problemas e necessidades dos docentes e dos estudantes; e desenvolverem novas formas de relacionamento e novos modos de trabalho ao trocarem experiências. Bem como refletir e questionar sobre o que está acontecendo dentro e fora da sala de aula.

Sobre isso, as novas DCNS contemplam um artigo sobre a formação de professores de engenharia para além da sala de aula. $O$ atual parecer destaca que a maioria do corpo docente na Engenharia não recebe formação para trabalhar o ensino, a pesquisa e a extensão de modo articulado. Nessa perspectiva, as DCNs afirmam que

É importante considerar ainda que, embora seja uma atividade inerente ao exercício do magistério, as atividades na graduação não agregam tanto valor para a progressão funcional quanto as atividades de pesquisa, isto sem mencionar o acesso a recursos de fomento. Isto posto, há aspectos que devem ser ressaltados, conforme abaixo discriminado:

- A capacitação didática pedagógica e para a gestão acadêmica do corpo docente;

- O equilíbrio entre os incentivos funcionais, os acadêmicos e os recursos oferecidos para as atividades de pesquisa, de extensão e para as atividades de ensino.

- O envolvimento de profissionais vinculados a empresas de Engenharia em atividades acadêmicas contextualizadas, por meio de Projetos de Formação, ou mesmo de contratações especiais.

Em outras palavras, é necessário priorizar a capacitação para o exercício da docência, visto que a implementação de projetos eficazes de desenvolvimento de competências exige conhecimentos específicos sobre meios, métodos e estratégias de ensino/aprendizagem (BRASIL, 2019, p. 31).

Apesar de concordar que o professor precisa de atualização constante, o foco não deve somente ser no desenvolvimento de competências ou o envolvimento dos estudantes com o ramo empresarial. Para Bazzo, Pereira e Linsingen (2016, p. 194-195),

Ele também deve ter consciência de seu entorno social, de seus compromissos e responsabilidades perante os coletivos que participa. Para 
formar tal cidadão-profissional consciente, assim acreditamos, precisamos de outros profissionais que extrapolem a visão puramente técnica das coisas à nossa volta. Assim, julgamos que, para formar formadores de profissionais técnicos, precisamos instigá-los e perturbá-los com a própria técnica e construir junto com eles reflexões que permitam a ambos os participantes desse processo discernir com certa clareza as estruturas epistemológicas, social e histórica que permeiam essa técnica. Devemos também instigá-los e perturbá-los dentro da lógica que permita internalizações de novos saberes.

O que é necessário é uma constante reflexão do porquê e para quem esse conhecimento está sendo desenvolvido. É importante, sim, que o professor esteja preparado para os novos desafios da sociedade, mas também considerar para onde essa civilização está caminhando.

É necessária uma estratégia que esteja em consonância com as mudanças no processo educativo e que privilegie a aprendizagem. Para isso, a formação docente deve ter consciência da sua responsabilidade, como salientaram os autores. Isso inclui vários aspectos: estratégias de ensino/aprendizagem, desenvolvimento humano, avaliação adequada, postura didática, relações profissionais, conscientização docente e principalmente, uma postura epistemológica.

\section{CONSIDERAÇÕES FINAIS}

Ao encaminhar o trabalho para as considerações finais é preciso registrar que as atividades do curso de engenharia estão totalmente relacionadas com o papel do professor que atua nesses cursos, pois uma formação baseada em competências, precisa de atividades interdisciplinares, com debates apropriados sobre os problemas contemporâneos, para que esses futuros engenheiros desenvolvam um pensamento crítico para agir de maneira humana, ética e cooperativa ao buscar as soluções para o desenvolvimento técnico e social.

Por isso, defende-se a importância da inclusão de atividades com enfoque CTS, que busquem compreender e encontrar subsídios para proporcionar um estudo crítico e interdisciplinar da ciência e da tecnologia no contexto atual. Para conduzir o estudante a uma visão mais ampla, é necessário integrar habilidades técnicas às competências; relacionando-as com as dimensões tecnológicas, científicas, econômicas, sociais, ambientais e éticas, e assim aproximar a formação do egresso com os desafios contemporâneos.

A partir disso, coloca-se em foco o poder interdisciplinar da matemática, ao explorar também variáveis sociais e humanas na utilização de modelos matemáticos e assim explorar todo o seu potencial. Para isso, é preciso que os cursos de engenharia adequem seus currículos por competências ao considerar e proporcionar aos futuros engenheiros o conhecimento da ambivalência das técnicas matemáticas. Isso significa ir além de práticas como modelar, prever, verificar e validar modelos através de métodos adequados, de modo a prepará-los para agirem com ética e serem responsáveis por essa matemática em ação. Mas, para que isso aconteça, torna-se necessário uma reflexão por parte dos professores.

Devido às exigências do mundo contemporâneo, a implantação de políticas e de programas institucionais permanentes de formação docente para a adequação das questões sociocientíficas é de extrema relevância. É necessário um programa de formação de professores para realmente atuarem na formação dos estudantes e não apenas nos 
círculos de pesquisa dentro dos grupos fechados da academia. Precisa-se de mais educadores que sejam pesquisadores, no sentido de leitores críticos e sensíveis que busquem soluções para os problemas que afetam a todos, dentro e fora da universidade.

Reforça-se a importância de um novo processo formativo para que se se aprofundem as questões humanas para além das formações técnicas e metodológicas. Para incluir essas discussões no meio acadêmico, é essencial um espaço formativo que se propiciem reflexões, de modo que se inicie um processo novo em busca das almejadas mudanças na educação e no mundo.

\section{REFERÊNCIAS}

BAZZO, W. A.; PEREIRA, L. T. V.; BAZZO, J. L. S. Conversando sobre educação tecnológica. 1. ed. Florianópolis: Editora da UFSC, 2014.

BAZZO, W. A.; PEREIRA, L. T. V.; LINSINGEN, I. von. Educação tecnológica: enfoques para o ensino de engenharia. 3. ed. Florianópolis: Editora da UFSC, 2016.

BRASIL. Conselho Nacional de Educação. Câmara de Educação Superior. Resolução CNE/CES 11, de 11 de março de 2002. Institui Diretrizes Curriculares Nacionais do Curso de Graduação em Engenharia. 2002. Disponível em:

<http://portal.mec.gov.br/cne/arquivos/pdf/CES112002.pdf>. Acesso em: 7 abr. 2021.

BRASIL, Conselho Nacional de Educação. Resolução CNE/CES no 2 de 24 de abril de 2019. Diretrizes Curriculares Nacionais do Curso de Graduação em Engenharia. Diário Oficial [da] República Federativa do Brasil, Brasília, DF, Seção I, p. 109, 23 de abril de 2019. Disponível em: http://portal.mec.gov.br/docman/marco-2019-pdf/109871-pces00119-1/file Acesso em: 2 abr. 2021.

CIVIERO, P. A. G. Educação matemática crítica e as implicações sociais da ciência e da tecnologia no processo civilizatório contemporâneo: embates para formação de professores de matemática. Tese (Doutorado em Educação Científica e Tecnológica) Universidade Federal de Santa Catarina, Florianópolis, UFSC, 2016.

GAFFURI, S. L. Bordin, L. CIVIERO, P. A. G.; BAZZO, W. A. O uso de modelos matemáticos na engenharia para discussão de questões sociocientíficas: variáveis sociais e humanas. Tear: Revista de Educação, Ciência e Tecnologia, v. 9, p. 1-13, 2020.

LEDOUX, M. L. P.; GONÇALVES, T. O. Identidade do professor que ensina matemática: elementos estruturantes do processo identitário. Revista de Matemática, Ensino e Cultura, Belém, ano 10, n.19, p. 79-93, maio/ago. 2015.

MORGADO, J. C. Identidade e profissionalidade docente: sentidos e (im)possibilidades. Ensaio: avaliação de políticas públicas educacionais, Rio de Janeiro, v. 19, n. 73, p. 793812, out./dez. 2011.

MONTEIRO, A. R. Auto-regulação profissional da educação: síntese preliminar do estudo solicitado pela Associação Nacional de Professores. Lisboa: CIE/FC, Universidade de Lisboa, 2009. 
PAIVA, M. A. V.; NACARATO, A. M. In: A formação do professor que ensina matemática: perspectivas e pesquisas. Belo Horizonte: Editora Autêntica, 2013.

PONTE, J. P. Da formação ao desenvolvimento profissional. In: ENCONTRO NACIONAL DE PROFESSORES DE MATEMÁTICA, 1998, Guimarães. Actas... Lisboa: APM, 1998, p. 27-44.

SKOVSMOSE, Ole. Um convite à Educação Matemática Crítica. Tradução: Orlando de Andrade Figueiredo. Campinas: Papirus, 2014.

SKOVSMOSE, Ole. Matemática em ação. In: BICUDO, Maria Aparecida; BORBA, Marcelo de Carvalho. Educação Matemática: pesquisa em movimento. 3. ed. São Paulo: Cortez, 2009.

SKOVSMOSE, Ole. Educação crítica: incerteza, matemática, responsabilidade. Tradução de M. A. V. Bicudo. São Paulo: Cortez, 2007.

TARDIF, Maurice. Saberes docentes e formação profissional. 16. ed. Vozes, RJ: 2014.

\title{
THE LINKS BETWEEN COURSE ACTIVITIES AND THE ROLE OF THE TEACHER WHO TEACHES MATHEMATICS IN ENGINEERING COURSES
}

\begin{abstract}
The complexity and diversification of requests that are currently being put in society have raised questions about the adequacy of the curricula of higher education courses, as well as the training of teachers in view of the technological and human development of students. When analyzing the training of engineers, this is even more challenging, since these professionals have their careers based on a job market that is constantly changing, which demands continuous updating and high training requirements. Therefore, this article analyzes the sixth and fourteenth article of the new National Curricular Guidelines for engineering courses (resolution CNE / CES no 2/2019), with the objective of making interlocutions between the activities of the course and the teaching practice, by reflecting on how mathematics teaching can contribute to analyze the solutions to contemporary challenges of this professional. For this, the importance of including activities with a focus on Science, Technology and Society (CTS) is defended, which seek to understand and find subsidies to provide a critical and interdisciplinary study of science and technology in the current context. To lead the student to a broader view of mathematical models, it is concluded that it is necessary to integrate technical skills with the interdisciplinary competences of mathematics, while also exploring social and human variables, relating them to technological, scientific, economic, social, environmental dimensions and ethics, and thus bring the formation of the egress closer to the social context.
\end{abstract}

Keywords: Engineering Education; National Curriculum Guidelines; Teacher training; Mathematical Education; CTS. 